\title{
BMJ Open Risks for comorbidity in children with atopic disorders: an observational study in Dutch general practices
}

\author{
David H J Pols, ${ }^{1}$ Arthur M Bohnen, ${ }^{1}$ Mark M J Nielen, ${ }^{2}$ Joke C Korevaar, ${ }^{2}$ \\ Patrick J E Bindels ${ }^{1}$
}

To cite: Pols DHJ, Bohnen AM, Nielen MMJ, et al. Risks for comorbidity in children with atopic disorders: an observational study in Dutch general practices. BMJ Open 2017;7:e018091. doi:10.1136/ bmjopen-2017-018091

- Prepublication history and additional material for this paper are available online. To view these files please visit the journal online (http://dx.doi. org/10.1136/bmjopen-2017018091).

Received 5 June 2017 Revised 18 September 2017 Accepted 5 October 2017

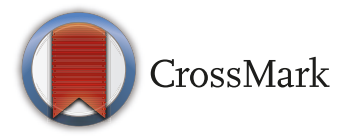

${ }^{1}$ Department of General Practice, Erasmus MC, University Medical Center, Rotterdam, The Netherlands

${ }^{2}$ NIVEL, Netherlands Institute for Health Services Research, Utrecht, The Netherlands

Correspondence to

Dr David H J Pols;

d.pols@erasmusmc.nl

\section{ABSTRACT}

Objective This study aimed to investigate both atopic and non-atopic comorbid symptoms and diseases in children with physician-diagnosed atopic disorders (atopic eczema, asthma and allergic rhinitis).

Methods All children aged 0-18 years listed in a nationwide primary care database (the Netherlands Institute for Health Services Research-Primary Care Database) with routinely collected healthcare data in 2014 were selected. Children with atopic disorders were matched on age and gender with non-atopic controls within the same general practice. A total of 404 International Classification of Primary Care codes were examined. Logistic regression analyses were performed to examine the associations between the presence of atopic disorders and (non-)atopic symptoms and diseases by calculating $\mathrm{ORs}$.

Results Having one of the atopic disorders significantly increased the risk of having other atopic-related symptoms, even if the child was not registered as having the related atopic disorder. Regarding non-atopic comorbidity, children with atopic eczema $(n=15530)$ were at significantly increased risk for (infectious) skin diseases (OR: 1.2-3.4). Airway symptoms or (infectious) diseases (OR: 2.1-10.3) were observed significantly more frequently in children with asthma $(n=7887)$. Children with allergic rhinitis $(n=6835)$ had a significantly distinctive risk of earnose-throat-related symptoms and diseases (OR: 1.5-3.9). Neither age nor gender explained these increased risks. Conclusion General practitioners are not always fully aware of relevant atopic and non-atopic comorbidity. In children known to have at least one atopic disorder, specific attention is required to avoid possible insufficient treatment and unnecessary loss of quality of life.

\section{INTRODUCTION}

Atopic disorders represent an important health problem in general practice. Acute upper airway infections, middle ear infections, warts, asthma and atopic eczema represent the five most prevalent paediatric diseases diagnosed in general practice ${ }^{1}$; allergic rhinitis is on the 12 th place on this list. However, limited data are available on the comorbidities of children with atopic disorders in primary care. ${ }^{2}$ In the present
Strengths and limitations of this study

- The present study used an extensive and representative general practice database.

- The large number of children gives the study substantial power and generalisability.

- A total of 404 International Classification of Primary Care codes were examined.

- A limitation regarding this type of explorative study is the unavoidable multiple testing.

study we refer to atopy as a (genetic) predisposition towards developing certain allergic hypersensitivity. Therefore the clinical manifestation of atopy is allergy. However, not all allergies are based on atopy. In this study the word 'atopic' refers to this genetically mediated predisposition, which did result in the clinical diagnosis by a general practitioner (GP) of atopic eczema, asthma and allergic rhinitis.

Associations have been shown between atopic disorders and other diseases in children, but in different clinical settings (eg, birth cohorts, hospitals or paediatric clinics). Demonstrated interrelations exist with (among others) diabetes, ${ }^{3-5}$ attention-deficit/hyperactivity disorder, ${ }^{6-8}$ autism $^{9-11}$ and obesity. ${ }^{12-14}$ According to other studies, the presence of some comorbidities may even influence the course of atopic disorders. For example, acute upper airway infections, especially in early childhood, are related to atopic disorders later in life. ${ }^{1516}$ Acute viral 'non-respiratory syncytial virus' bronchiolitis in infants aged $<6$ months is linked with an increased risk of developing asthma. ${ }^{17}$ The developing immune system of a child might be affected by frequent or severe infections of the middle ear, resulting in increased risk for asthma and atopic eczema. ${ }^{18}$ On the other hand, otitis media with effusion is associated with allergic rhinitis. ${ }^{19-21}$ The quality of 
life of a child with atopic disorders can be significantly improved by providing sufficient treatment.

To our knowledge no study has investigated the complete range of potential comorbidities in children with atopic disorders in a general practice setting. A relevant question could be: Are children with atopic disorders at increased risk for non-atopic symptoms or diseases? Awareness by GPs of these risks may reduce the probability that relevant comorbidity is not diagnosed. To study possible associations between atopic disorders and 404 different symptoms and diseases, an extensive and representative nationwide general practice database is explored using a cross-sectional design. The design of this study allows new hypotheses to be generated, providing valuable input for future research.

\section{METHODS}

\section{Study population}

All non-institutionalised residents in the Netherlands are registered in a general practice, even if they do not visit the GP on a regular basis. The Netherlands Institute for Health Services Research-Primary Care Database (NIVEL-PCD) is based on routinely recorded data in electronic health records (EHRs) of all listed patients in the participating practices. In 2014, about 500 general practices participated, including data of about 1700000 patients (www.nivel.nl/en/dossier/ nivel-primary-care-database), which is over $10 \%$ of the total Dutch population. EHR data include a variety of information regarding type of consultation, morbidity and prescriptions. Data available for 2014 are representative for the Dutch population. ${ }^{22}$.

\section{ICPC and episodes of care}

Primary care physicians (gatekeepers for the Dutch healthcare system) recorded morbidity using the International Classification of Primary Care (ICPC), a classification method for primary care that is accepted by the WHO. ${ }^{23}$ It has been translated in 22 languages and is now widely used for the routine collection of data on episodes of care, but also in encounter studies. ${ }^{24}$ Routinely collected general practice computer data, aggregated into large databases, are used for epidemiological research. ${ }^{25}$ Hippisley-Cox et $a l^{26}$ illustrate how routine clinical data, in selected high recording practices (this selection criterion was also applied in the present study), are now reaching reasonable levels of accuracy and completeness for a range of key variables. According to Britt $e t a l^{27}$, morbidity data actively collected by GPs provide a reliable overview of morbidity managed in general practice.

Dutch GPs cluster relevant consultations, prescriptions and referrals, in ICPC-classified 'episodes of care'. An episode of care is a health problem or disease from its first presentation to the GP to the last presentation for the same problem. Atopic disorders are labelled with ICPC codes: S87 (atopic eczema), R96 (asthma) and R97 (allergic rhinitis). ICPC codes specific for food allergies are not available.

For the present study, only morbidity data from EHRs of general practices with sufficient data quality were used that fulfilled the following criteria: (1) at least 500 listed patients (standard practice: 2350 patients), (2) complete morbidity registration (defined as $\geq 46$ weeks / year) and (3) sufficient ICPC coding of diagnostic information (defined as $\geq 70 \%$ of the recorded disease episodes labelled with an ICPC code; the average ICPC coding in a Dutch general practice is $>95 \%$ ). The following descriptive data were routinely collected: period in which the individual child was registered in the general practice, the unique code of the GP practice, the child's gender, and year and quarter of birth.

\section{Children with atopic disorders}

For each child (0-18 years), a minimum follow-up of 3 years was required ( $\mathrm{eg}$, data had to be available for 2012-2014) for the present study to reduce the risk of registration bias. For this reason, only data for children aged $\geq 2$ years are presented here. In the Netherlands, GPs see about $72 \%$ of their patient population at least once a year. ${ }^{28}$ We considered a 3-year follow-up period to be sufficient time for a GP to diagnose a child with (atopic) disorders. Furthermore, in order not to miss any relevant atopic diagnosis, when available, the EHRs from 2002 to 2014 were examined. Since GPs inevitably work with probability diagnoses, there is a risk of misclassification. To select cases with a higher probability of a clinically relevant disorder, ICPC codes and their related episodes of care can be corrected. In practice, an atopic episode of care was maintained if (between 2002 and 2014) the parent of the child had at least contacted the GP twice in that episode of care and had received at least two relevant prescriptions. If the child did not meet these criteria, the child was considered not to have that atopic disorder ${ }^{29}$ and was excluded from the study (this child could not be used as a control patient, to make sure that controls did not have any atopic disorder). If a child was diagnosed with an atopic disorder for the first time during 2014, the child was considered to have the atopic disorder that whole year. In the present study, the atopic diagnosis was based on the physician's assessment and was considered to be a chronic problem.

\section{Atopic triad}

A recent meta-analysis supported the hypothesis that there might be a fourth distinct group of children with all three atopic disorders, in contrast to the traditional classification of children with asthma or allergic rhinitis or atopic eczema. ${ }^{30}$ To learn more about this potentially unique group of children, 'atopic triad' episodes were developed for research purposes. These episodes were only created when a child was diagnosed with all three atopic disorders, based on available data from EHRs in the period of 2002-2014. 


\section{Symptoms and diseases studied}

After establishing which child had an atopic disorder (see above), a child was considered prevalent for a specific symptom or disease if the child had at least one active episode of care for that symptom or disorder between January and December of 2014. All ICPC codes that describe a symptom or a disease were examined, with the exception of trauma-related ICPC codes, ICPC codes not relevant for children (eg, presbycusis), pregnancy, childbearing, family planning, sexually transmitted diseases and social problems, leaving 404 different ICPC codes. Furthermore, since different classifications are used for eczema, there is a risk of misclassification. The ICPC system distinguishes the codes S86 (seborrheic dermatitis), S87 (atopic eczema), S88 (contact dermatitis/eczema another) and S89 (diaper rash). Since clinical differentiation can be very difficult, especially between S87 and S88, S88 was excluded from our analyses, to get more reliable results for 'true' atopic eczema (S87).

\section{Design}

An observational study design was used in which cases with one atopic disorder were matched with controls without any atopic disorder. For each child with atopic disorders, one matched control patient was selected (not diagnosed with an atopic disorder) within the same general practice, based on age and gender in 2014. Controls were only matched if a $100 \%$ match on age, gender and general practice with a child with atopic disorders was determined. ORs were calculated for children who solely had atopic eczema, asthma or allergic rhinitis and therefore no other atopic comorbidity. Online supplementary appendix 1 presents a list of all the ICPC codes that were examined. A 1:1 ratio was chosen to be able to include as many pairs of cases and controls as possible, allowing the results to carry more weight and making the conclusions more generalisable to future populations. In the present study, a $1: 2$ ratio would have resulted in dropping over $40 \%$ of the cases.

\section{Statistical analyses}

Logistic regression analysis was performed to study associations between the presence of atopic disorders and (non-)atopic comorbid symptoms and diseases in children. Similarly, associations between atopic triad and the above-mentioned comorbid symptoms and diseases were examined. Due to multiple testing, only associations with $\mathrm{p} \leq 0.001$ were considered statistically significant. All associations were tested for the modifying effects of age and gender. In case of a significant effect $(p \leq 0.01)$, associations were also presented for subgroups for age (2-6 vs 7-12 vs 13-18 years) and gender (boy vs girl). Finally, due to the hierarchical structure of the data (patients registered in general practices), a multilevel logistic regression analysis was performed to test whether clustering effects influenced our findings. All
Table 1 General characteristics of the total study population

\begin{tabular}{lrcl}
\hline & \multicolumn{2}{l}{$\begin{array}{l}\text { Age in } \\
\text { years (SD) }\end{array}$} & Male (\%) \\
\hline Only atopic eczema & 15530 & $8.7(4.5)$ & 48.2 \\
Only asthma & 7887 & $10.7(4.5)$ & 59.0 \\
Only allergic rhinitis & 6835 & $13.5(3.5)$ & 57.8 \\
Atopic triad & 559 & $11.6(4.0)$ & 61.4 \\
\hline
\end{tabular}

NB: Children in the first three groups had only one of the three atopic disorders: that is, they had the disorder mentioned, but none of the other disorders, whereas children in the atopic triad group had all three disorders.

analyses were conducted on Stata V.13 and Excel 2010. Prevalence rates are presented in percentages.

\section{RESULTS}

\section{General characteristics}

There were 409312 childrenidentified in the NIVEL-PCD in 2014, initially including 70494 children with at least one atopic disorder. However, for a child with atopic disorder to be included in this study, one matched control patient had to be available (ie, a child without an atopic disorder). There were 21285 children with atopic eczema identified, of whom 15530 children had atopic eczema without another atopic disorder. For children with asthma, 13196 children were identified, of whom 7887 had asthma only and no other atopic disorders. In children with allergic rhinitis, 11483 were identified, of whom 6835 had allergic rhinitis without another atopic disorder. Finally, 559 children had all three atopic disorders. All the children in these groups were selected from 316 different general practices participating in NIVEL-PCD. Clustering effects did not influence our findings (table 1).

\section{Atopic eczema}

A substantial part of the significantly related comorbidity for children with atopic eczema concerns skin diseases such as (among others) warts (OR: 1.2), localised rash (OR: 1.5), pruritus (OR: 1.7), impetigo (OR: 1.7), dermatophytosis (OR: 1.8), urticaria (OR: 1.8), molluscum contagiosum (OR: 1.9) and psoriasis (OR: 3.4). Otitis externa (OR: 1.6) and blepharitis (OR: 1.5) were also significantly associated with atopic eczema. The symptom diagnosis of wheezing (OR: 2.0), which could be attributed to asthma, is noteworthy since these children were not diagnosed or coded in the EHRs with asthma. The same applies to symptoms associated with allergic rhinoconjunctivitis, such as sneezing/ nasal congestion (OR: 2.0) and allergic conjunctivitis (OR: 2.0). Older children with atopic eczema were at increased risk to develop a localised rash (OR: 1.3 to 2.3) and impetigo (OR: 1.5 to 2.7). Compared with boys, girls had an increased risk to develop a localised 
Table 2 Significantly $(\mathrm{p} \leq 0.001)$ associated comorbidity in children diagnosed with only atopic eczema $(\mathrm{Ec})$ and at least 3-year follow-up versus controls (non-atopic children) $(n=31060)$

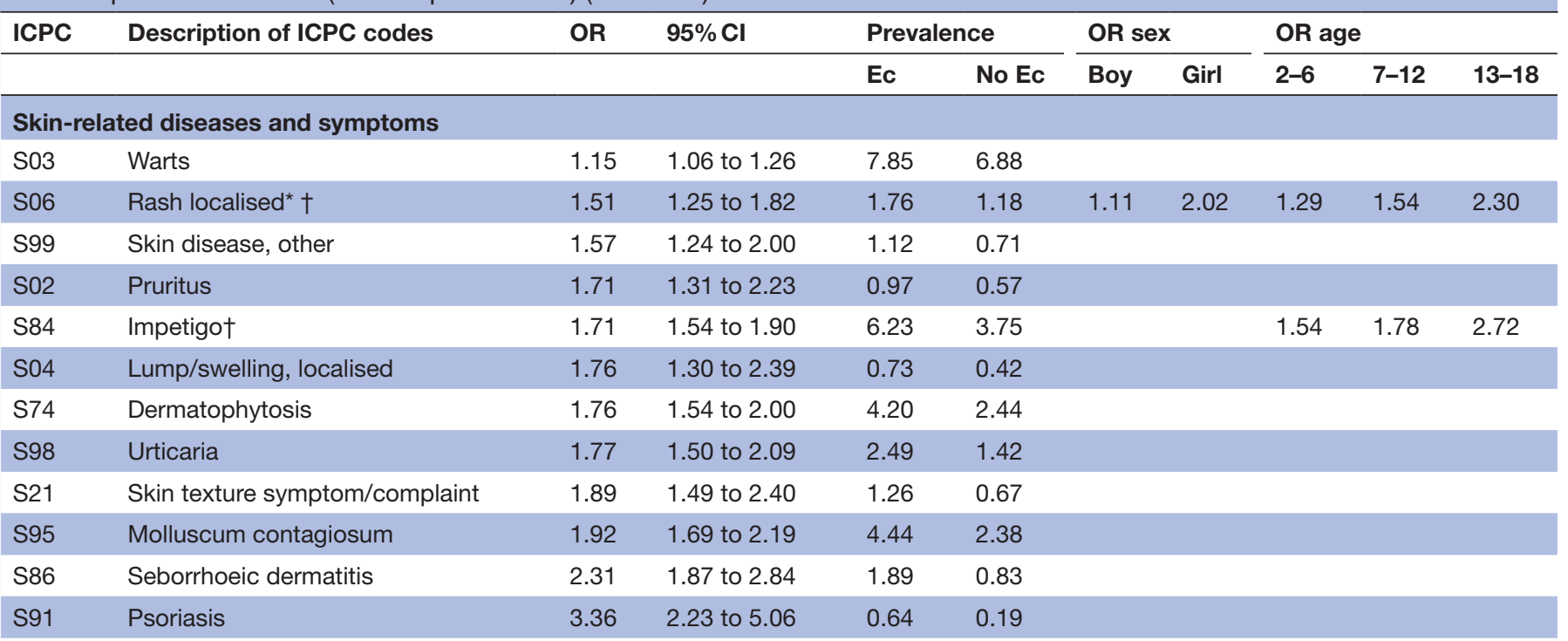

Airway-related diseases and symptoms

\begin{tabular}{lllllllll} 
R05 & Cough & 1.29 & 1.17 to 1.43 & 5.94 & 4.67 & & \\
R74 & Upper respiratory infection, acute & 1.33 & 1.23 to 1.43 & 10.42 & 8.13 & & \\
R78 & Acute bronchitis/bronchiolitis & 1.49 & 1.22 to 1.80 & 1.66 & 1.13 & & \\
R04 & Breathing problem, other* & 1.55 & 0.97 to 2.48 & 0.29 & 0.19 & 0.91 & 3.58 \\
R03 & Wheezing & 1.95 & 1.30 to 2.92 & 0.45 & 0.23 & & \\
\hline
\end{tabular}

Ear-nose-throat-related diseases and symptoms

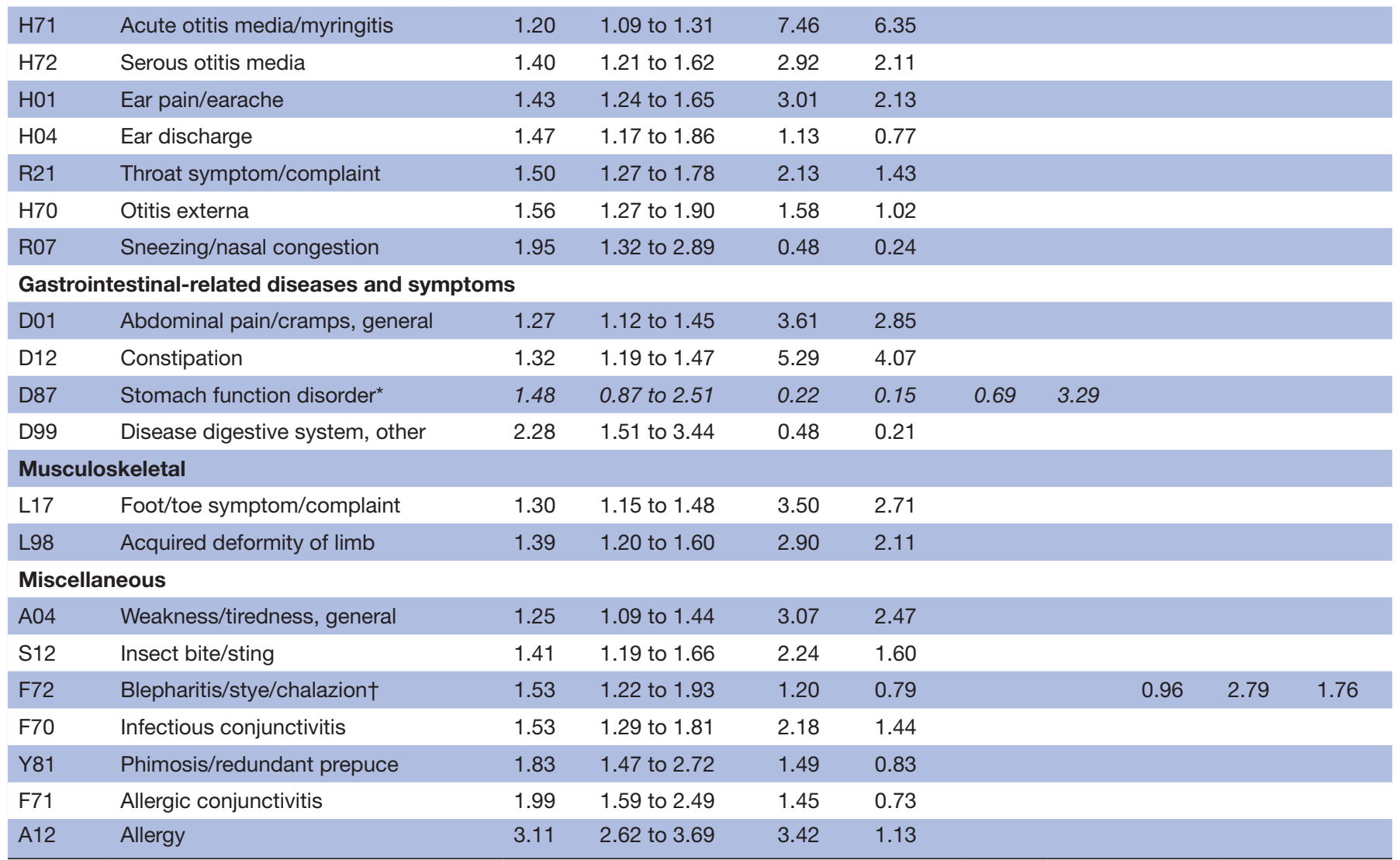

Italics mean overall model not significant.

*Significant $(p \leq 0.01)$ influence of gender.

†Significant $(p \leq 0.01)$ influence of age.

ICPC, International Classification of Primary Care. 
Table 3 Significantly $(p \leq 0.001)$ associated comorbidity in children diagnosed with only asthma (As) and at least 3-year followup versus controls (non-atopic children) $(n=15774)$

\begin{tabular}{|c|c|c|c|c|c|c|c|c|c|c|}
\hline \multirow[t]{2}{*}{ ICPC } & \multirow[t]{2}{*}{ Description of ICPC codes } & \multirow[t]{2}{*}{ OR } & \multirow[t]{2}{*}{$95 \% \mathrm{Cl}$} & \multicolumn{2}{|c|}{ Prevalence } & \multicolumn{2}{|c|}{ OR sex } & \multicolumn{3}{|c|}{ OR age } \\
\hline & & & & As & No As & Boy & Girl & $2-6$ & $7-12$ & $13-18$ \\
\hline \multicolumn{11}{|c|}{ Skin-related diseases and symptoms } \\
\hline S98 & Urticaria & 2.10 & 1.61 to 2.73 & 2.21 & 1.07 & & & & & \\
\hline \multicolumn{11}{|c|}{ Airway-related diseases and symptoms } \\
\hline R05 & Cough & 2.14 & 1.86 to 2.46 & 7.99 & 3.93 & & & & & \\
\hline $\mathrm{R} 77$ & Laryngitis/tracheitis, acute & 2.34 & 1.54 to 3.56 & 0.94 & 0.41 & & & & & \\
\hline R74 & Upper respiratory infection & 2.35 & 2.09 to 2.64 & 12.34 & 5.78 & & & & & \\
\hline R81 & Pneumonia & 4.04 & 3.03 to 5.37 & 2.97 & 0.76 & & & & & \\
\hline R78 & Acute bronchitis/bronchiolitis $†$ & 4.80 & 3.78 to 6.11 & 4.79 & 1.05 & & & 3.74 & 5.63 & 8.09 \\
\hline R91 & Chronic bronchitis & 5.66 & 3.14 to 10.23 & 0.93 & 0.16 & & & & & \\
\hline R02 & Shortness of breath/dyspnoea & 7.74 & 5.05 to 11.87 & 2.31 & 0.30 & & & & & \\
\hline R03 & Wheezing & 10.30 & 4.73 to 22.42 & 0.90 & 0.09 & & & & & \\
\hline \multicolumn{11}{|c|}{ Ear-nose-throat-related diseases and symptoms } \\
\hline $\mathrm{H} 76$ & Foreign body in ear* & 0.86 & 0.40 to 1.85 & 0.15 & 0.18 & 2.51 & 0.20 & & & \\
\hline H01 & Ear pain/earache & 1.45 & 1.16 to 1.81 & 2.46 & 1.71 & & & & & \\
\hline H71 & Acute otitis media/myringitis & 1.52 & 1.32 to 1.76 & 6.44 & 4.4 & & & & & \\
\hline $\mathrm{H} 70$ & Otitis externa & 1.60 & 1.22 to 2.08 & 1.79 & 1.13 & & & & & \\
\hline $\mathrm{R} 75$ & Sinusitis acute/chronic & 1.90 & 1.32 to 2.75 & 1.05 & 0.56 & & & & & \\
\hline
\end{tabular}

\section{Gastrointestinal-related diseases and symptoms}

\begin{tabular}{|c|c|c|c|c|c|c|c|c|c|c|}
\hline D89 & Inguinal hernia* & 0.76 & 0.37 to 1.57 & 0.16 & 0.22 & 0.27 & 4.52 & & & \\
\hline D01 & Abdominal pain/cramps, general & 1.40 & 1.16 to 1.69 & 3.32 & 2.40 & & & & & \\
\hline D06 & Abdominal pain, localised, other & 1.43 & 1.15 to 1.77 & 2.59 & 1.83 & & & & & \\
\hline D73 & Gastroenteritis, infection & 1.60 & 1.25 to 2.05 & 2.10 & 1.33 & & & & & \\
\hline D10 & Vomiting & 2.02 & 1.37 to 2.97 & 0.99 & 0.49 & & & & & \\
\hline L15 & Knee symptom/complaint $†$ & 1.11 & 0.90 to 1.37 & 2.42 & 2.18 & & & 1.34 & 1.49 & 0.97 \\
\hline L12 & Hand symptom/complaint* & 1.37 & 1.09 to 1.71 & 2.27 & 1.67 & 1.00 & 2.13 & & & \\
\hline L98 & Acquired deformity of limb & 1.40 & 1.16 to 1.68 & 3.54 & 2.56 & & & & & \\
\hline L99 & Musculoskeletal disease, other & 1.52 & 1.22 to 1.89 & 2.66 & 1.78 & & & & & \\
\hline A04 & Weakness/tiredness, general & 1.39 & 1.17 to 1.65 & 4.04 & 2.97 & & & & & \\
\hline N01 & Headache & 1.51 & 1.21 to 1.89 & 2.49 & 1.66 & & & & & \\
\hline F70 & Infectious conjunctivitis & 1.72 & 1.31 to 2.27 & 1.78 & 1.04 & & & & & \\
\hline $\mathrm{T} 10$ & Growth delay & 1.82 & 1.35 to 2.44 & 1.60 & 0.89 & & & & & \\
\hline T83 & Overweight & 2.09 & 1.41 to 3.10 & 0.98 & 0.47 & & & & & \\
\hline T82 & Obesity & 2.47 & 1.50 to 4.05 & 0.68 & 0.28 & & & & & \\
\hline F71 & Allergic conjunctivitis & 2.55 & 1.85 to 3.49 & 1.72 & 0.68 & & & & & \\
\hline A12 & Allergy & 3.40 & 2.74 to 4.23 & 4.55 & 1.38 & & & & & \\
\hline
\end{tabular}

Italics mean overall model not significant.

*Significant $(p \leq 0.01)$ influence of gender.

†Significant $(p \leq 0.01)$ influence of age.

ICPC, International Classification of Primary Care. 
Table 4 Significantly $(p \leq 0.001)$ associated comorbidity in children diagnosed with only allergic rhinitis (AR) and at least 3-year follow-up versus controls (non-atopic children) $(n=13670)$

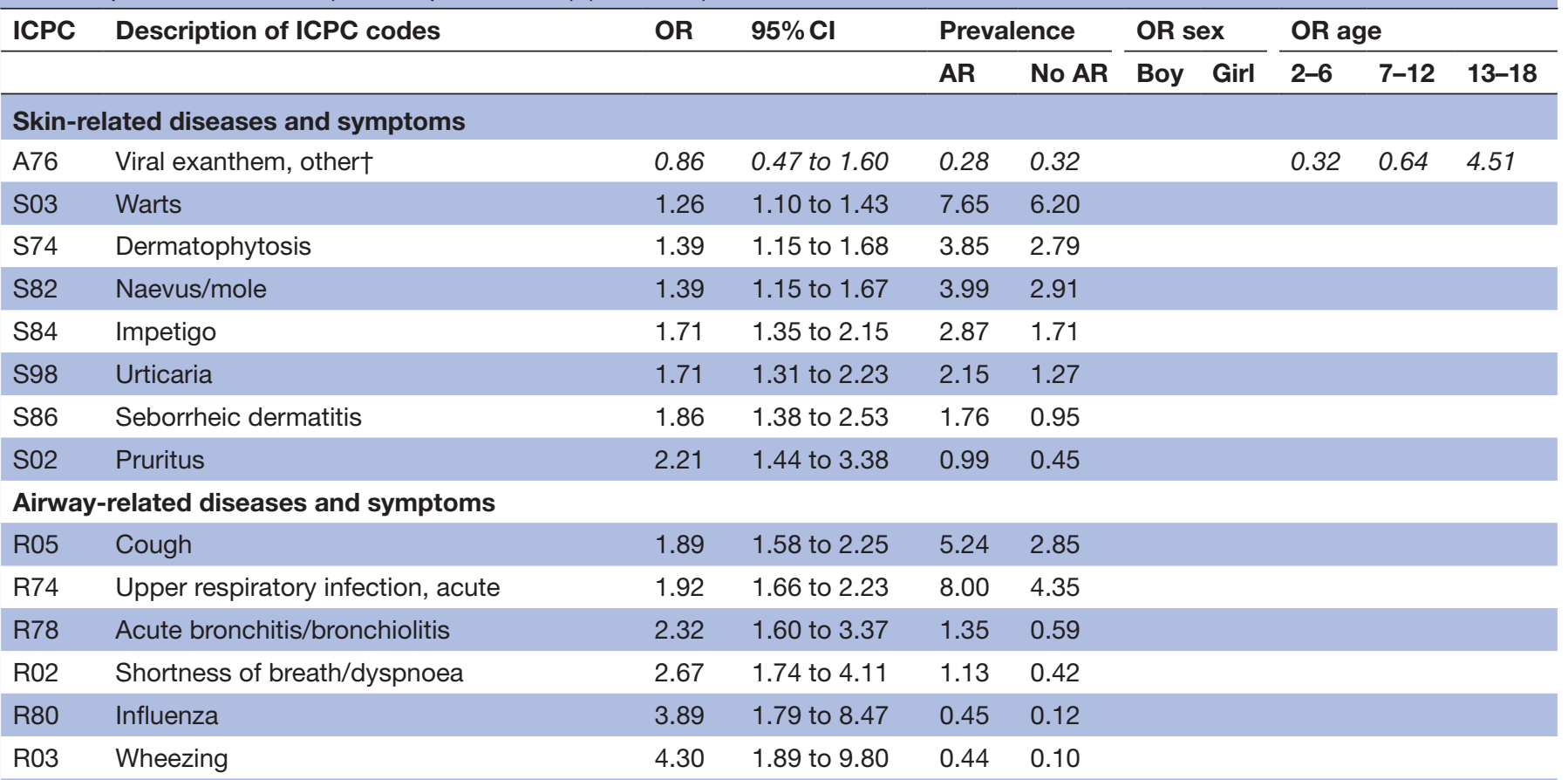

Ear-nose-throat-related diseases and symptoms

\begin{tabular}{|c|c|c|c|c|c|c|c|c|c|c|}
\hline $\mathrm{R} 21$ & Throat symptom/complaint & 1.48 & 1.20 to 1.84 & 3.13 & 2.14 & & & & & \\
\hline H01 & Ear pain/earache & 1.87 & 1.36 to 2.56 & 1.62 & 0.88 & & & & & \\
\hline R90 & Hypertrophy tonsils/adenoids $†$ & 1.92 & 1.34 to 2.74 & 1.30 & 0.69 & & & 3.22 & 2.80 & 1.04 \\
\hline R08 & Nose symptom/complaint, other & 2.62 & 1.72 to 4.00 & 1.14 & 0.44 & & & & & \\
\hline $\mathrm{R} 07$ & Sneezing/nasal congestion & 3.93 & 2.57 to 6.01 & 1.54 & 0.40 & & & & & \\
\hline D06 & Abdominal pain, localised, other & 1.76 & 1.39 to 2.22 & 2.90 & 1.67 & & & & & \\
\hline D73 & Gastroenteritis, presumed infection* & 1.96 & 1.42 to 2.71 & 1.59 & 0.82 & 1.29 & 3.39 & & & \\
\hline \multicolumn{11}{|c|}{ Musculoskeletal } \\
\hline L98 & Acquired deformity of limb & 1.36 & 1.15 to 1.62 & 4.54 & 3.37 & & & & & \\
\hline N19 & Speech disorder* & 1.18 & 0.85 to 1.65 & 1.17 & 0.99 & 0.89 & 2.43 & & & \\
\hline N01 & Headache & 1.45 & 1.18 to 1.78 & 3.29 & 2.30 & & & & & \\
\hline P24 & Specific learning problem & 1.45 & 1.18 to 1.78 & 3.37 & 2.37 & & & & & \\
\hline $\mathrm{A} 04$ & Weakness/tiredness, general & 1.58 & 1.35 to 1.85 & 6.10 & 3.96 & & & & & \\
\hline F70 & Infectious conjunctivitis & 1.73 & 1.28 to 2.32 & 1.76 & 1.02 & & & & & \\
\hline S12 & Insect bite/sting & 1.92 & 1.40 to 2.63 & 1.67 & 0.88 & & & & & \\
\hline F72 & Blepharitis/stye/chalazion* & 1.95 & 1.36 to 2.79 & 1.27 & 0.66 & 1.21 & 3.29 & & & \\
\hline A12 & Allergy & 4.02 & 3.15 to 5.13 & 4.70 & 1.21 & & & & & \\
\hline F71 & Allergic conjunctivitis & 5.44 & 4.08 to 7.25 & 4.29 & 0.82 & & & & & \\
\hline
\end{tabular}

Italics mean overall model not significant.

${ }^{*}$ Significant $(p \leq 0.01)$ influence of gender.

†Significant $(p \leq 0.01)$ influence of age.

ICPC, International Classification of Primary Care. 


\begin{tabular}{|c|c|c|c|c|c|}
\hline \multirow[t]{2}{*}{ ICPC } & \multirow[t]{2}{*}{ Description of ICPC codes } & \multirow[t]{2}{*}{ OR } & \multirow[t]{2}{*}{$95 \% \mathrm{Cl}$} & \multicolumn{2}{|l|}{ Prevalence } \\
\hline & & & & Atopic triad & No atopic triad \\
\hline R05 & Cough & 2.42 & 1.43 to 4.10 & 8.59 & 3.76 \\
\hline L17 & Foot/toe symptom/complaint & 3.25 & 1.63 to 6.50 & 6.08 & 1.97 \\
\hline R74 & Upper respiratory infection, acute & 3.75 & 2.33 to 6.04 & 14.13 & 4.29 \\
\hline F71 & Allergic conjunctivitis & 6.79 & 2.35 to 19.60 & 4.65 & 0.72 \\
\hline A12 & Allergy & 17.83 & 7.15 to 44.43 & 13.77 & 0.89 \\
\hline
\end{tabular}

ICPC, International Classification of Primary Care.

rash (OR: 2.0 vs 1.1), breathing problems (OR: 3.6 vs 0.9 ) and stomach function disorder (OR: 3.3 vs 0.7 ) (table 2).

\section{Asthma}

Noteworthy are asthma-related symptoms that were diagnosed separately, such as shortness of breath/ dyspnoea (OR: 7.7) and wheezing (OR: 10.3). Furthermore, children with asthma were presented to their GPs more frequently for airway-related infections such as acute laryngitis/tracheitis (OR: 2.3), acute upper respiratory infection (OR: 2.4), pneumonia (OR: 4.0) and acute bronchitis (OR: 4.8). In children with asthma, there seems to be a higher risk for the development of gastrointestinal symptoms, for example, general abdominal pain/cramps (OR: 1.4), localised abdominal pain (OR: 1.4), constipation (OR: 1.4) and vomiting (OR: 2.0). Acute bronchitis (OR: 3.7 to 8.1) was diagnosed more often in older children. Inguinal hernias were seen more frequently in girls than in boys (OR: 4.5 vs 0.3) (table 3).

\section{Allergic rhinitis}

Children with allergic rhinitis were presented to their GPs more frequently for ear-nose-throat-related symptoms and diseases. Among others, the following were diagnosed more often: throat symptom/complaint (OR: 1.5), ear pain/earache (OR: 1.9), hypertrophy tonsils/ adenoids (OR: 1.9), acute/chronic sinusitis (OR: 2.0), nose symptom (OR: 2.6) and sneezing/nasal congestion (OR: 3.9). Furthermore, symptoms associated with atopic eczema (pruritus; OR: 2.2) and asthma (shortness of breath/dyspnoea (OR: 2.7) and wheezing (OR: 4.3)) were seen more frequently. Also, when a child was diagnosed with allergic rhinitis, there was a substantial risk for the development of gastrointestinal symptoms (constipation (OR: 1.5) and localised abdominal pain (OR: 1.8)). Hypertrophy of the tonsils was diagnosed less frequently when children got older (OR: 3.2 to 1.0 ). On the other hand, children were more frequently diagnosed with a viral exanthem when they became older (OR: 0.3 to 4.5 ). A presumed gastrointestinal infection (OR: 3.4 vs 1.3), speech disorder (OR: 2.4 vs 0.9 ) and blepharitis/style/ chalazion (OR: 3.3 vs 1.2 ) were diagnosed more frequently in girls with allergic rhinitis (table 4).

\section{Atopic triad}

Having all three atopic disorders is relatively rare, with only a few symptoms and diseases being significantly related. The risk for developing an 'allergy' that the GP considers relevant to register in the EHR can be considered high (OR: 17.8). Allergic conjunctivitis (OR: 6.8) is also frequently seen in children with all three atopic disorders (table 5).

\section{DISCUSSION \\ Main findings}

The present study used an extensive and representative general practice database. ${ }^{22}$ The large number of children gives the study substantial power and generalisability. This could also allow evaluation of possible links between atopic disorders and rare childhood diseases. This study showed that children with atopic disorders have an increased risk for the development of both atopic and non-atopic diseases and symptoms. Children diagnosed with one atopic disorder were frequently diagnosed by their GP with symptoms associated with one of the (other) atopic disorder(s). This suggests that GPs are not always fully aware of relevant atopic comorbidity, or at least do not label it correctly. Two examples support this hypothesis. First of all, a child diagnosed with atopic eczema is also diagnosed with pruritus, suggesting possible misclassification. Second, a child with atopic eczema who is presented with 'wheeze' or 'dyspnea' is at a higher risk for the development of asthma compared with a child without atopic eczema. A GP should be aware of this increased risk, since it could result in insufficient treatment of a child. However, a GP could also use symptom-related ICPC codes deliberately when the purpose is to record a provisional diagnosis (eg, wheeze as the provisional diagnosis of asthma). Regarding non-atopic comorbidity, strong associations were found between the atopic disorder and diseases and symptoms related to the same organ system. For example, children with atopic eczema are at increased risk for the development of other skin diseases, children with asthma are at risk of other airway diseases, and children with allergic rhinitis are at risk of ear-nose-throat-related symptoms and diseases. 
Gastrointestinal and musculoskeletal diseases and symptoms were also seen more frequently in children with atopic disorders. When exploring possible interactions of age and gender in children with one atopic disorders, no clear patterns arose.

\section{Interpretation of findings in relation to previously published work}

Children with atopic eczema had an increased risk of developing infectious skin diseases such as warts, impetigo, dermatophytosis and molluscum contagiosum. The common aetiology could be the barrier dysfunction of the skin in children with atopic eczema. This barrier dysfunction is also seen in psoriasis, a disease that, according to the present study, is associated with atopic eczema (OR: 3.4). They share some common pathological backgrounds such as barrier dysfunction and enhanced interleukin-22 expression. ${ }^{31}$ Although the clinical pictures of these two diseases can be very different, the observed association could also suggest misclassification among these two chronic skin diseases that are often confused for one another. Otitis externa and blepharitis both had significant ORs. These disorders could in fact be an expression of atopic eczema.

Children with asthma seem to have been presented to their GPs more frequently for airway-related infections such as acute laryngitis/tracheitis, acute upper respiratory infection, pneumonia and bronchitis. This is in agreement with another primary healthcare study. ${ }^{2}$ An explanation for this could be that airway infections increase asthma symptoms or vice versa, and that asthma resulted in increased susceptibility for infection, which increased their motivation to visit the GPs. Furthermore, the awareness of parents is likely to be increased when a child suffers from asthma, since such an infection could predispose for an asthma exacerbation.

Children with allergic rhinitis were presented to their GPs more frequently for ear-nose-throat-related symptoms and diseases. However, even more striking are the asthma-related symptoms. Both shortness of breath (OR: 2.7) and wheeze (OR: 4.3) were frequently seen in children with allergic rhinitis. There is strong evidence that allergic rhinitis has an adverse impact on asthma severity. ${ }^{32}$ Because allergic rhinitis can provoke asthma symptoms, allergic rhinitis symptoms should be taken more seriously by GPs to reduce insufficient treatment.

Gastrointestinal-related symptoms are also frequently diagnosed by GPs in children with atopic disorders. This is in accordance with a study in adults in a primary care setting. ${ }^{33}$ These symptoms could be related to IgE-mediated food allergies or in rare cases even to eosinophilic oesophagitis, which is associated with atopic disorders ${ }^{34}$; however, in children, abdominal pains can also be a general expression of not feeling well. Unfortunately, the ICPC classification system does not cover the above-mentioned gastrointestinal diseases with unique code, and therefore gastrointestinal-related symptoms might have been used by the GP to label these diseases.
Some associations described in the literature were not confirmed in the present study, for example, serous otitis media in patients with allergic rhinitis, ${ }^{1921}$ and inflammatory bowel disease, ${ }^{3536}$ leukaemia ${ }^{37} 38$ and diabetes ${ }^{39} 40$ in patients with atopic disorders. The prevalences of some of these disorders are low and a cross-sectional design (as used in the present study) might not have enough power to prove these relationships.

\section{Strengths and limitations of this study}

Using general practice databases (by means of a cross-sectional design) also has its limitations. First of all, a limitation for the present study is the GP's choice for ICPC coding of an episode of care. For example, a child with a wheeze could either be labelled as 'asthma' (R96) or labelled as 'wheeze' (R03). This could result in both overestimation or underestimation of asthma. To decrease this risk of overestimation regarding atopic disorders, some episodes were corrected in order to increase the clinical relevance of the atopic disorder of interest. However, the risk of underestimation was not tackled, since too many assumptions need to be made. The second limitation regarding this type of explorative study is the unavoidable multiple testing. Although conservative $p$ values were used, type 1 errors cannot be avoided. In this study, some suggested associations might in fact reflect these type 1 errors. Third, because data on socioeconomic status, tobacco smoke exposure and other lifestyle-related risk factors are not recorded in NIVEL-PCD, we cannot rule out the effect of these risk factors on the observed relations. However, since the children with atopic disorders were matched with controls within the same general practice, all children are most likely living in the same neighbourhoods, and therefore the effect of most of the earlier mentioned risk factors is expected to be small. Fourth, children with atopic disorders might be presented to the GP more frequently than non-atopic children. And although this may be more representative of parental fears, rather than an indication of morbidity, it can result in more detected morbidity in children with atopic disorders and could partly explain some of the associations found. In future research, the number of consultations might need to be taken into account in the analyses. Fifth, in the present study the diagnoses are based on a physician's assessment and not on confirmed sensitisation pattern for allergens. According to the Dutch medical guideline for eczema, ${ }^{41}$ GPs are not advised to determine these sensitisation patterns, since these do not have any clinical consequences. Although atopy is clearly associated with atopic eczema, the role of $\operatorname{IgE}$ sensitisation in atopic eczema still needs further study. ${ }^{42}$ Also in children with allergic rhinitis, sensitisation patterns do not have added value if the medical history clearly suggests, for example, a pollen allergy. ${ }^{43}$ Only when the cause of the rhinitis is uncertain the determination of sensitisation patterns adds value. The medical guidelines for asthma in children advise to determine sensitisation patterns, ${ }^{44}$ since it can help diagnose allergic asthma ${ }^{45}$ and because it 
could have clinical consequences. Finally, it is important to acknowledge the uncertainty of GPs to make a diagnosis of asthma or allergic rhinitis in young children (eg, under the age of 6 ).

\section{Implications for future research and practice}

First of all, could comorbidity data be used to create proxies that could support GPs in identifying children with atopic disorders that are not labelled as such? For example, could comorbidity data be incorporated in 'clinical decision support systems' to improve early diagnosis of both atopic and non-atopic disorders. Second, how is the quality of life of these children with atopic disorders affected by the associated comorbidity? GPs should be aware of the described associations when treating a child with atopic disorder, since the quality of life of a child with atopic disorder could be improved by paying more attention to diagnosis and treatment of these related disorders. Furthermore, one must be aware that atopic disorders and associated symptoms and diseases may well persist into adulthood.

\section{CONCLUSIONS}

The present study shows that children with atopic disorders have an increased risk of clinically relevant comorbidity, both atopic and non-atopic. GPs may not always be fully aware of relevant atopic and non-atopic comorbidity. In children known to have at least one atopic disorder, specific attention is required to avoid possible insufficient treatment and unnecessary loss of quality of life.

Acknowledgements The authors thank Petra ten Veen (database specialist, NIVEL) for her help with the selection of eligible patients and Samana Jamsheed for her help with the data extraction.

Contributors Study conception and design: DHJP, MMJN, JCK, PJEB, AMB. Acquisition of data: DHJP, MMJN. Analysis and interpretation of data: DHJP, MMJN. Drafting of manuscript: DHJP. Critical revision: MMJN, JCK, PJEB, AMB. Guarantor: MMJN, AMB.

Funding This research received no specific grant from any funding agency in the public, commercial or not-for-profit sectors.

\section{Competing interests None declared.}

Ethics approval Dutch law allows the use of EHRs for research purposes under certain conditions. According to this legislation, it is not necessary to obtain informed consent from patients or approval from a medical ethics committee for this type of observational study that contains no directly identifiable data (Dutch Civil Law, Article 7: 458). Therefore, no waiver of ethical approval was obtained from an institutional review board (IRB) or ethics committee. The authors had no access to any identifying information at any moment during the analysis of the data.

Provenance and peer review Not commissioned; externally peer reviewed.

Data sharing statement Data will be available from the repository of Data Archiving and Networked Services (DANS; www.dans.knaw.nl).

Open Access This is an Open Access article distributed in accordance with the Creative Commons Attribution Non Commercial (CC BY-NC 4.0) license, which permits others to distribute, remix, adapt, build upon this work non-commercially, and license their derivative works on different terms, provided the original work is properly cited and the use is non-commercial. See: http://creativecommons.org/ licenses/by-nc/4.0/

(C) Article author(s) (or their employer(s) unless otherwise stated in the text of the article) 2017. All rights reserved. No commercial use is permitted unless otherwise expressly granted.

\section{REFERENCES}

1. Van der Linden MW, Van Suijlekom-Smit LWA, Schellevis FG, et al. Tweede Nationale Studie naar ziekten en verrichtingen in de huisartspraktijk. Culemborg 2005:38.

2. Jacob L, Keil T, Kostev K. Comorbid disorders associated with asthma in children in Germany - National analysis of pediatric primary care data. Pediatr Allergy Immunol 2016;27:861-6.

3. Fsadni P, Fsadni C, Fava S, et al. Correlation of worldwide incidence of type 1 diabetes (DiaMond) with prevalence of asthma and atopic eczema (ISAAC). Clin Respir J 2012;6:18-25.

4. Huang S-W, Hitchcock J. Influence of the $T_{H} 1 / T_{H} 2$ paradigm: the prevalence of asthma and allergic diseases in patients wit type 1 diabetes in the United States. Pediatr Asthma Allergy Immunol 2002;15:195-9.

5. Villa-Nova H, Spinola-Castro AM, Garcia FE, et al. Prevalence of allergic diseases and/or allergic sensitisation in children and adolescents with type 1 diabetes mellitus. Allergol Immunopathol 2015;43:157-61.

6. Chen MH, Su TP, Chen YS, et al. Asthma and attention-deficit/ hyperactivity disorder: a nationwide population-based prospective cohort study. J Child Psychol Psychiatry 2013;54:1208-14.

7. Chen MH, Su TP, Chen YS, et al. Is atopy in early childhood a risk factor for ADHD and ASD? a longitudinal study. J Psychosom Res 2014;77:316-21.

8. Schmitt J, Apfelbacher C, Heinrich J, et al. [Association of atopic eczema and attention-deficit/hyperactivity disorder - meta-analysis of epidemiologic studies]. Z Kinder Jugendpsychiatr Psychother 2013;41:35-44.

9. Chen M-H, Su T-P, Chen Y-S, et al. Comorbidity of allergic and autoimmune diseases in patients with autism spectrum disorder: a nationwide population-based study. Res Autism Spectr Disord 2013;7:205-12.

10. Jyonouchi $\mathrm{H}$. Autism spectrum disorders and allergy: observation from a pediatric allergy/immunology clinic. Expert Rev Clin Immunol 2010;6:397-411.

11. Lin T-Y, Lin P-Y, Su T-P, Tp S, et al. Autistic spectrum disorder, attention deficit hyperactivity disorder, and allergy: Is there a link? A nationwide study. Res Autism Spectr Disord 2014;8:1333-8.

12. Yao TC, Ou LS, Yeh KW, et al. Associations of age, gender, and BMI with prevalence of allergic diseases in children: PATCH study. $J$ Asthma 2011;48:503-10.

13. KreißI S, Radon $\mathrm{K}$, Dressel $\mathrm{H}$, et al. Body mass index change and atopic diseases are not always associated in children and adolescents. Ann Allergy Asthma Immunol 2014;113:440-4.

14. Weinmayr G, Forastiere F, Büchele G, et al. Overweight/obesity and respiratory and allergic disease in children: international study of asthma and allergies in childhood (ISAAC) phase two. PLoS One 2014;9(12):e113996.

15. Juntti $\mathrm{H}$, Kokkonen J, Dunder $\mathrm{T}$, et al. Association of an early respiratory syncytial virus infection and atopic allergy. Allergy 2003;58:878-84.

16. Sidorchuk A, Wickman M, Pershagen G, et al. Cytomegalovirus infection and development of allergic diseases in early childhood: interaction with EBV infection? J Allergy Clin Immunol 2004;114:1434-40.

17. Koponen P, Helminen M, Paassilta M, et al. Preschool asthma after bronchiolitis in infancy. Eur Respir J 2012;39:76-80.

18. Maclntyre EA, Heinrich J. Otitis media in infancy and the development of asthma and atopic disease. Curr Allergy Asthma Rep 2012;12:547-50.

19. Alles R, Parikh A, Hawk L, et al. The prevalence of atopic disorders in children with chronic otitis media with effusion. Pediatr Allergy Immunol 2001;12:102-6.

20. Caffarelli C, Savini E, Giordano S, et al. Atopy in children with otitis media with effusion. Clin Exp Allergy 1998;28:591-6.

21. Kwon C, Lee HY, Kim MG, et al. Allergic diseases in children with otitis media with effusion. Int $J$ Pediatr Otorhinolaryngol 2013;77:158-61.

22. Nielen MMJ, Spronk I, Davids R, et al. Accountability incidence and prevalence of health problems in the Dutch general practice in 2012. Nivel 2012:20-4.

23. Lamberts $\mathrm{H}$, Wood $\mathrm{M}$. The birth of the International Classification of Primary Care (ICPC). Serendipity at the border of Lac Léman. Fam Pract 2002;19:433-5.

24. Soler JK, Okkes I, Wood M, et al. The coming of age of ICPC: celebrating the 21 st birthday of the international classification of primary care. Fam Pract 2008;25:312-7.

25. de Lusignan S, van Weel C. The use of routinely collected computer data for research in primary care: opportunities and challenges. Fam Pract 2006;23:253-63. 
26. Hippisley-Cox J, Hammersley V, Pringle M, et al. How useful are General Practice Databases for research? analysis of the accuracy and completeness in one research network. Health Inform J 2004;10:91-109.

27. Britt $H$, Angelis $M$, Harris $E$. The reliability and validity of doctorrecorded morbidity data in active data collection systems. Scand J Prim Health Care 1998;16:50-5.

28. Hupkens $\mathrm{C}$, Swinkels $\mathrm{H}$. Ongeveer drie kwart bezoekt jaarlijks huisarts en tandarts. CBS. 2013 https://www.cbs.nl/nl-nl/nieuws/ 2013/27/ongeveer-drie-kwart-bezoekt-jaarlijks-huisarts-en-tandarts (updated 2 July 2013).

29. Pols DHJ, Nielen MMJ, Korevaar JC, et al. Reliably estimating prevalences of atopic children: an epidemiological study in an extensive and representative primary care database. NPJ Prim Care Respir Med. In Press. 2017;27:23.

30. Pols DH, Wartna JB, van Alphen El, et al. Interrelationships between atopic disorders in children: a meta-analysis based on isaac questionnaires. PLoS One 2015;10:e0131869.

31. Miyagaki T, Sugaya M. Recent advances in atopic dermatitis and psoriasis: genetic background, barrier function, and therapeutic targets. J Dermatol Sci 2015;78:89-94.

32. Deliu M, Belgrave D, Simpson A, et al. Impact of rhinitis on asthma severity in school-age children. Allergy 2014;69:1515-21.

33. Powell N, Huntley B, Beech T, et al. Increased prevalence of gastrointestinal symptoms in patients with allergic disease. Postgrad Med J 2007;83:182-6.

34. Cianferoni A, Spergel J. Eosinophilic esophagitis: a comprehensive review. Clin Rev Allergy Immunol 2016;50:159-74.

35. Kappelman M, Galanko J, Porter C, et al. Young faculty clinical investigator award association of pediatric inflammatory bowel disease with other immune-mediated diseases. J Pediatr Gastroenterol Nutr 2009;49:E67-E8.

36. Kappelman MD, Galanko JA, Porter CQ, et al. Association of paediatric inflammatory bowel disease with other immune-mediated diseases. Arch Dis Child 2011;96:1042-6.

37. Linabery AM, Jurek AM, Duval S, et al. The association between atopy and childhood/adolescent leukemia: a meta-analysis. Am J Epidemiol 2010;171:749-64.

38. Hughes AM, Lightfoot T, Simpson J, et al. Allergy and risk of childhood leukaemia: results from the UKCCS. Int $J$ Cancer 2007;121:819-24.

39. Tzeng ST, Hsu SG, Fu LS, Ls F, et al. Prevalence of atopy in children with type 1 diabetes mellitus in central Taiwan. J Microbiol Immunol Infect 2007;40:74-8.

40. Meerwaldt R, Odink RJ, Landaeta R, et al. A lower prevalence of atopy symptoms in children with type 1 diabetes mellitus. Clin Exp Allergy 2002;32:254-5.

41. Dirven-Meijer PC, De Kock CA, Nonneman MMG, et al. NHGStandaard Eczeem. Huisarts Wet 2014;57:240-52.

42. Flohr C, Johansson SG, Wahlgren CF, et al. How atopic is atopic dermatitis? J Allergy Clin Immunol 2004;114:150-8.

43. Sachs APE, Berger MY, Lucassen P, et al. NHG-Standaard Allergische en niet-allergische rhinitis (Eerste herziening). Huisarts Wet 2006;49:254-65.

44. Bindels PJE, Van de Griendt EJ, Grol MH, et al. NHG-Standaard Astma bij kinderen (Derde herziening). Huisarts Wet 2014;57:70-80.

45. Eysink PE, ter Riet G, Aalberse RC, et al. Accuracy of specific lgE in the prediction of asthma: development of a scoring formula for general practice. Br J Gen Pract 2005;55:125-31. 